\title{
Memorias de las desapariciones. Los vecinos del Centro Clandestino de Detención del Hospital Posadas, Buenos Aires, Argentina
}

Memories of the Disappeareances: Neighbours of the Clandestine Detention Centre of the Posadas Hospital in Buenos Aires, Argentina

Mémoires des disparitions. Les voisins du Centre Clandestin de Détention de l'Hôpital Posadas, Buenos Aires, Argentine

Emilio Crenzel

\section{OpenEdition}

\section{Journals}

Edición electrónica

URL: http://journals.openedition.org/rccs/1707

DOI: $10.4000 /$ rccs. 1707

ISSN: $2182-7435$

Editor

Centro de Estudos Sociais da Universidade de Coimbra

Edición impresa

Fecha de publicación: 1 marzo 2010

Paginación: 79-99

ISSN: 0254-1106

Referencia electrónica

Emilio Crenzel, « Memorias de las desapariciones. Los vecinos del Centro Clandestino de Detención del Hospital Posadas, Buenos Aires, Argentina », Revista Crítica de Ciências Sociais [En línea], 88 | 2010, Puesto en línea el 01 octubre 2012, consultado el 19 abril 2019. URL : http://journals.openedition.org/ rccs/1707; DOl : 10.4000/rccs. 1707 


\section{Memorias de las desapariciones. Los vecinos del Centro Clandestino de Detención del Hospital Posadas, Buenos Aires, Argentina}

En este artículo se examinan las memorias que circulan entre vecinos del Hospital Posadas, ubicado en Haedo, provincia de Buenos Aires, Argentina, sobre la represión política en tiempos de la última dictadura militar (1976-1983). Tras el golpe de Estado, funcionó en el Hospital Posadas un Centro Clandestino de Detención en el cual se mantenían personas cautivas ilegalmente, en condición de desaparecidas. Así, en el Hospital Posadas convivieron, simultáneamente, las prácticas relativas al cuidado y restauración de la salud y la perpetración de torturas y asesinatos. En este trabajo se analizarán los recuerdos y olvidos de estos hechos entre diversos vecinos que habitaban, en tiempos de la dictadura, en las inmediaciones del Hospital Posadas. Específicamente, se indagará qué experiencias tuvieron con la violencia de Estado, en particular con el sistema de desaparición de personas, y cómo ellas han quedado inscriptas en sus memorias personales. Por último, se analizarán la información que circulaba y los grados de conocimiento que poseían estos vecinos sobre los atributos, naturaleza y responsables de las desapariciones en el hospital mientras éstas se perpetraban.

Palabras clave: Argentina; desapariciones; dictadura militar; Hospital Posadas; memorias; représión política; terrorismo de Estado; vecinos.

Palavras-chave: Argentina; desaparecidos; ditadura militar; Hospital Posadas; memória; repressão política; terrorismo de Estado; vizinhança.

\section{Introducción}

En este artículo se examinan las memorias que circulan entre vecinos del Hospital Posadas, ubicado en la localidad de Haedo, en la provincia de Buenos Aires, Argentina, sobre la represión política durante la última dictadura militar que gobernó el país entre 1976 y $1983 .{ }^{1}$ En 1976, tras el último golpe

\footnotetext{
${ }^{1}$ Agradezco a los evaluadores anónimos de la Revista Crítica de Ciências Sociais los comentarios y sugerencias efectuados a este artículo.
} 
de Estado, funcionó en dependencias del Hospital Posadas un Centro Clandestino de Detención en el cual se mantenían cautivas de manera ilegal a personas previamente secuestradas y que se hallaban en condición de desaparecidas. En este predio, estuvieron cautivos profesionales y técnicos del propio hospital y otras personas sospechosas, para las fuerzas represivas, de participar en actividades "subversivas". De este modo, en el Hospital Posadas convivieron la vida y la muerte, mediante el simultáneo ejercicio de las prácticas relativas al cuidado y restauración de la salud y la perpetración de torturas y asesinatos. En este trabajo, se analizarán los recuerdos y olvidos de estos hechos presentes entre diversos vecinos que habitaban, en tiempos de la dictadura, en las inmediaciones del Hospital Posadas. En función de ello, se indagarán qué experiencias concretas tuvieron estos vecinos con la violencia de Estado, una de cuyas manifestaciones estaba localizada en el seno del propio hospital, y cómo esas experiencias han quedado inscriptas en sus memorias personales. Por último, se analizarán los grados de conocimiento que poseían estos vecinos sobre los atributos, naturaleza y responsables de las desapariciones mientras éstas se perpetraban.

En el plano teórico, este trabajo se inscribe en el campo abierto por las investigaciones que han comenzado a analizar los vínculos entre las sociedades civiles y regímenes o procesos bajo los cuales se perpetraron violencias extremas (Laqueur, 1980; Browning, 1992, Theidon, 2004, y Johnson y Heiz-Reuband, 2006, entre otros). Para el caso argentino, desde 1984 se instaló con fuerza en el espacio público la proposición del informe Nunca Más, elaborado por la Comisión Nacional sobre la Desaparición de Personas (CONADEP) creada por el Presidente Alfonsín tras el retorno de la democracia para investigar el destino de los desaparecidos causados por la represión estatal, que postuló la ignorancia y ajenidad de la sociedad argentina respecto de la práctica de las desapariciones (CONADEP, 1984). ${ }^{2}$

Desde otras perspectivas, investigaciones académicas recientes destacaron los mecanismos de normalización del terror y el desplazamiento de la culpabilización hacia las víctimas (Malamud Goti, 2000: $94-96$ y 138-139); remarcaron las estrategias de adaptación que desenvolvió la sociedad civil ante la dictadura (Vezzetti, 2002: 50-51 y 63) y propusieron la existencia de variaciones en la percepción pública de la violencia de Estado, al compás de los cambios operados en la legitimidad de la dictadura y del paulatino desvelamiento de sus crímenes (Novaro y Palermo, 2002: 133-135 y 486).

\footnotetext{
${ }^{2}$ Para la historia de la elaboración, usos y resignificaciones del informe Nunca Más, véase Crenzel (2008).
} 
Entre estos trabajos sobresalió, por su aceptación, el de Calveiro quien propuso la existencia de un saber y no saber simultáneo, proceso entendido como una negación social de un conocimiento imposible de no haber sido adquirido sobre el "sistema concentracionario". La sociedad, según la autora, conocía la existencia de los Centros Clandestinos de Detención los cuales eran una realidad negada y sabida, simultáneamente. La sociedad, concluye, "eligió no ver" (Calveiro, 1995: 147).

Estas páginas pretenden discutir esta última proposición y su contracara, la del informe Nunca Más, por entender que ambas postulan una imagen homogénea del conocimiento que circulaba sobre el sistema de desaparición en la sociedad argentina. Parto de la premisa de que ignorar y conocer son dos extremos de un arco con muchos matices. El proceso de conocimiento involucra la formación de estructuras de causalidad que constituyen las ideas y representaciones que los individuos y grupos se forjan y a partir de las cuales se explican la realidad. En ese proceso, participan determinaciones estructurales, prácticas sociales y valores morales y normativos que le dan sentido (Mannheim, 1993). Por ello, se trata de identificar los procesos que operan en la constitución de los marcos epistémicos de los sujetos que promueven, limitan u obstaculizan la elaboración de conocimiento (Piaget, 1985: 268-70) y, en este caso, los que se movilizan ante experiencias de violencia extrema y terror (Cohen, 2001). Este trabajo, a partir del análisis de las memorias de la dictadura de los vecinos del Hospital Posadas, propone la existencia de una gran heterogeneidad en el conocimiento de los atributos y la naturaleza del sistema de desaparición la cual fue producto de las propiedades específicas de este sistema represivo.

\section{El hospital Posadas durante la dictadura militar}

La práctica sistemática de las desapariciones, a partir del golpe de Estado de marzo de 1976, supuso dos cambios radicales con respecto a los grados y formas que había asumido la intensa violencia política que experimentó Argentina durante el siglo xx. En primer lugar, a diferencia de la represión que hasta entonces había ejercido el Estado contra militantes políticos o sindicales, las desapariciones expresaron una decisión de exterminio que supuso la eliminación física de miles de personas. En segundo lugar, involucraron una forma novedosa de ejercicio de la muerte por causas políticas, su práctica clandestina. ${ }^{3}$ Estas particularidades, distinguen, además, a

\footnotetext{
3 En 1984, la CONADEP registró 8960 casos de desaparición forzada de personas (CONADEP, 1984). Por su parte, los organismos de derechos humanos postulan la existencia de 30000 desaparecidos.
} 
la dictadura argentina del resto de las que, en los años setenta, se establecieron en los países del Cono Sur de América latina. ${ }^{4}$

Las desapariciones consistían en la detención o en el secuestro de personas efectuados por personal militar o policial, uniformados o vestidos de civil. Las personas secuestradas eran conducidas a lugares ilegales de cautiverio, los centros clandestinos, donde eran torturadas y, en su mayoría, asesinadas. En paralelo, las diferentes instituciones del Estado negaban toda responsabilidad en su destino. En el encubrimiento de este crimen fue decisiva la configuración de un espacio novedoso de cautiverio, los Centros Clandestinos de Detención. Pese a prolongar las degradaciones y torturas perpetradas en la cárcel política, su carácter ilegal y oculto escindía a los cautivos del mundo exterior, promovía su olvido, limitaba la solidaridad y la denuncia y permitía, sin obstáculos, la tortura y el asesinato de los desaparecidos.

A diferencia de otras experiencias concentracionarias, en Argentina la infraestructura material de los centros clandestinos mayoritariamente conjugó un doble valor de uso. Al estar localizados primordialmente en unidades militares o comisarías se desarrollaban en ellos las actividades habituales de esas dependencias y, simultáneamente, oficiaban como espacios de cautiverio, tortura y exterminio de los desaparecidos. Ello ponía en un contacto cotidiano al personal policial o militar con las prácticas ilegales que se desarrollaban en esas dependencias. A diferencia de estos espacios que, por su naturaleza, limitaban la visibilidad de lo que allí ocurría, el centro clandestino del Hospital Posadas estaba localizado en un centro de salud de carácter público. Si bien el Centro Clandestino funcionaba en una edificación independiente, ubicada en los fondos del hospital, originariamente destinada a la vivienda de su director y en la cual, de hecho funcionaron hasta el golpe de Estado los grupos de atención psiquiátrica, por el hospital circulaban diariamente médicos, enfermeras, técnicos, personal administrativo y centenares de pacientes y, por ello, estaba expuesto a una mayor y más heterogénea visibilidad social.

El Hospital Posadas está ubicado en el partido de Haedo, en la provincia de Buenos Aires. Fue construido en la década de 1950, durante el segundo gobierno de Juan Domingo Perón, y funcionó parcialmente en tareas de investigación médica para atender enfermos con afecciones pulmonares crónicas y tuberculosis hasta 1972. En 1973, ingresaron por

\footnotetext{
${ }^{4}$ En Uruguay, predominó la cárcel prolongada; en Chile, las desapariciones representan un tercio del total de muertos y en Brasil, al igual que en Uruguay, alcanzaron un centenar de casos. Al respecto, ver SERPAJ (1989); Comisión Nacional de Verdad y Reconciliación (1991); y Arquidiocese de São Paulo (1985), respectivamente.
} 
concurso médicos jóvenes formados en el sistema de residencias, con una dedicación exclusiva a su actividad profesional, y un alto compromiso con la medicina pública.

El proceso de radicalización política que recorría el país tuvo también su expresión en el Hospital Posadas. Ya bajo el gobierno del peronista de izquierda Héctor Cámpora, el 14 de junio de 1973, el hospital fue tomado por médicos, técnicos y empleados, quienes impulsaban un centro de salud de "puertas abiertas" a la comunidad en contraposición al modelo de centro de salud especializado que, entendían, condensaba el hospital (Álvarez, 2003: 67). También, postulaban el reemplazo del director designado por la dictadura militar saliente y la designación en su reemplazo del doctor Julio Rodríguez Otero, a quien lograron imponer en el cargo mediante fuertes movilizaciones el 10 de julio de 1973 (Bonanotte et al., s/f). Según un informe de la Dirección de Inteligencia de la Policía de la Provincia de Buenos Aires (DIPBA), obrante en el archivo de la Comisión Provincial por la Memoria de esa provincia, también participaron de la toma residentes de la villa de emergencia lindante con el hospital (Batallón de Inteligencia 601, 1976).

Los meses siguientes se caracterizaron por la ampliación y aumento de la actividad hospitalaria. Creció el número de camas de internación, y se habilitaron nuevos servicios: Cardiología, Terapia Intensiva, Ortopedia y Traumatología. Paralelamente, se desarrolló una intensa relación entre los vecinos de los barrios aledaños y el Posadas, a través de la Asociación de Profesionales del hospital y el sindicato Asociación de Trabajadores del Estado que representaba a una importante porción de los trabajadores. Enclavado en un área que en ese entonces tenía mucha actividad fabril, en el Posadas también se realizaron numerosas asambleas de trabajadores de establecimientos de la zona. En 1974 bajo el tercer gobierno de Perón, la izquierda peronista es desplazada de la conducción del Hospital y asume su dirección el doctor Arturo Pimentel, apoyado por una custodia armada.

Tras ello, la escalada represiva fue en aumento hasta que el 28 de marzo de 1976, cuatro días después del golpe de Estado, el hospital fue ocupado militarmente mediante un operativo conducido por el general Reinaldo Bignone, quien era delegado de la Junta Militar en el Ministerio de Bienestar Social, y luego fuera presidente de facto entre junio de 1982 y diciembre de 1983. Del operativo, participaron cien soldados, apoyados por tanques, carros blindados, helicópteros, camiones, integrantes de la policía de la provincia de Buenos Aires y de la Fuerza Aérea (Auto de procesamiento, 2007).

Las fuerzas militares efectuaron requisas, se apostaron en las entradas del Hospital portando listas con los nombres de los trabajadores, que debieron 
formar fila mientras se determinaban las detenciones. Más de cincuenta trabajadores fueron arrestados y llevados a diferentes centros clandestinos de detención o a cárceles legales donde estuvieron presos durante meses sin causas penales, sus domicilios fueron allanados y sus familiares torturados. Las requisas y las detenciones se extendieron a los barrios aledaños al hospital (ibid.).

Con el procedimiento militar asume como interventor del hospital el Coronel Médico Di Benedetto quien declaró en comisión a todo el personal, licenció a todo el personal detenido y despidió a más de 150 empleados y profesionales. En paralelo, en la prensa gráfica se calificaba al Hospital Posadas como un reducto subversivo que prestaba apoyo a la guerrilla atendiendo a sus heridos, se remarcaba la existencia de un quirófano clandestino, depósitos de armas y túneles secretos que comunicaban al hospital con los barrios aledaños. ${ }^{5}$

El 14 de abril de 1976 asumió la dirección del hospital el Coronel Médico (RE) Julio R. Estévez quien contrató a un grupo de ex policías y policías en actividad apodados por los empleados del hospital como "SWAT", en alusión a una serie televisiva norteamericana popular en aquel momento, un grupo policial de elite que enfrentaba situaciones críticas. Los "SWAT" sembraron el terror en el hospital. En paralelo, comenzaron a utilizarse las dependencias de reunión de los grupos de atención psiquiátrica como Centro Clandestino de Detención y desaparecen once trabajadores del hospital: médicos, enfermeras y técnicos (Auto de procesamiento, 2007). Tras el retorno de la democracia, la CONADEP inspeccionó el hospital Posadas y confirmó la existencia en su predio de un Centro Clandestino de Detención (CONADEP, 1984: 148 y 149). En paralelo, el personal del hospital formó diversas comisiones que participaron de las movilizaciones de los organismos de derechos humanos, y promovieron la evocación de los desaparecidos del hospital.

\section{Los vecinos del hospital Posadas}

En 1976, al producirse el golpe de Estado, existían dos localizaciones habitacionales lindantes con el Hospital posadas. Por un lado, la villa de emergencias Carlos Gardel, que fuera inicialmente un barrio de casas de clase media empobrecida, y que se conformó en 1969 con gente proveniente en su mayoría del interior del país. Por otro lado, el barrio de monoblocks Mariano Pujadas, que se terminó de construir en 1973, con el nombre de Barrio Villa Sarmiento. El 22 de agosto de 1974, fue renombrado por la

\footnotetext{
5 Véase La Prensa, 7 de abril de 1976: 4. Editorial: "Lo que se pretendió negar”.
} 
comisión de vecinos como Mariano Pujadas, al cumplirse dos años de que dieciséis integrantes de los grupos guerrilleros fueran fusilados en la localidad de Trelew, en el sur del país, tras un intento fallido de fuga de una cárcel. Mariano Pujadas, uno de ellos, era militante de la organización "Montoneros", surgida en 1970 durante la dictadura de la Revolución Argentina (1966-1973), que había alcanzado una importante inserción entre los estudiantiles universitarios y en ciertas barriadas populares. Ambos barrios albergaban, a mediados de los años setenta, 3500 y 9000 personas respectivamente (Bonanotte et al., s/f).

En mayo de 1973, los médicos del hospital Posadas habían instalado en esos barrios consultores pediátricos que atendían las necesidades sanitarias de sus habitantes, e implementaron varias campañas de vacunación masiva. Estas actividades se llevaron a cabo a partir de los lazos que establecieron con los líderes de manzana de la villa Carlos Gardel, con el club de madres, con el centro de alfabetización de adultos y el jardín de infantes que funcionaban allí. Otro tanto hicieron en el barrio Mariano Pujadas, donde establecieron relaciones con los representantes de los vecinos, elegidos en cada monoblock y escalera, con la guardería, la administración del barrio, y el club de madres. En ambos casos, también, establecieron vínculos con los diferentes partidos de izquierda, en especial el Partido Comunista, y con los grupos armados peronistas y marxistas de la zona.

Las páginas que siguen retratan, a partir de una aproximación exploratoria basada en veinte entrevistas realizadas entre vecinos de ambos barrios, sus evocaciones sobre la violencia política previa al golpe de Estado y su conocimiento sobre la existencia del Centro Clandestino ubicado en el predio del hospital Posadas y el sistema de desaparición forzada de personas. Dado el carácter exploratorio del trabajo, sus conclusiones no pretenden ser representativas, esto es dar cuenta de las memorias del universo elegido como objeto de estudio, los vecinos del hospital Posadas. Se limitan, en cambio, a proponer ciertas ideas que deberán ser contrastadas a partir de un mayor cúmulo de evidencias. La interpretación de las entrevistas comprende la prevención teórico-metodológica de considerar la afectación de las respuestas ofrecidas ante preguntas retrospectivas sobre eventos traumáticos y de fuerte presencia en el espacio público, ocurridos hace treinta años. En función de ello, las respuestas de los entrevistados fueron analizadas como un tipo de "evidencia histórica" no perdiendo de vista los juegos de lenguaje y sentido en el que participan los entrevistados, propios de las luchas por la memoria en las que se inscribe todo testimonio. Esto es, situando al testimonio en referencia "a aquellos procesos sociales y políticos de construcción del sentido en los que, con mayor o menor consistencia 
participan los actores" (Nun, 1984: 148) y enmarcándolos en los contextos de enunciación que establecen las claves narrativas y explicativas, los límites "de lo decible" (Pollak, 1990: 12) y no sólo en su adherencia a los hechos, sino también en su alejamiento a los mismos, cuando surge la imaginación, el simbolismo, el deseo (Portelli, 1991: 43).

\section{La memoria militante y el terror}

Del conjunto de entrevistados se distinguen dos personas. Su característica es haber sido militantes políticos en el barrio adyacente al hospital y haber participado de actividades asociativas en el propio hospital Posadas. Pablo, de 63 años, fue militante en el hospital de una organización político militar, el Ejército Revolucionario del Pueblo, de orientación guevarista. Pablo, actualmente médico, tiene compañeros de militancia desaparecidos, y otros que revistieron bajo la condición de presos políticos en las cárceles legales de la dictadura. Pablo recuerda que la represión política en el barrio comenzó antes del golpe de Estado de 1976. En 1975, en el contexto de los enfrentamientos bajo los gobiernos peronistas, la derecha de ese partido destroza con una bomba el monolito que había sido colocado un año antes en el barrio homenajeando a Pujadas. Luego, señala, los grupos paramilitares asesinan a Julio Aravena, militante del partido "Unión Cívica Radical" - segundo en importancia en el país y de tendencia de centro -, empleado del Banco Hipotecario, que tenía una estrecha relación con la comisión del barrio y a un dirigente portuario cuyo cadáver aparece en la zona. Pablo conocía del secuestro de varios compañeros de militancia y sabía de la responsabilidad de las Fuerzas Armadas y policiales en esos hechos pero, tras el golpe de Estado y la intensificación de la represión, fue perdiendo lazos con ellos y posibilidades de compartir y discutir sobre lo que estaba sucediendo. Por cierto, recuerda, los lazos entre el hospital y la comunidad de los barrios adyacentes se habían ido quebrando durante el año $1975 .{ }^{6}$

$\mathrm{Al}$ evocar la situación en el barrio Pujadas tras el golpe, recuerda que

El barrio estaba militarizado, y aquellos moradores que estaban endeudados en sus créditos hipotecarios habían comenzado a ser desalojados por el ejército, era terrible la represión. [...] Lo primero que las autoridades militares hicieron cuando ocupan el hospital fue construir un paredón y un doble alambrado. El barrio cada dos por tres sufría operativos, que bajaban con helicópteros y con todo, se metían escalera por escalera, departamento por departamento, buscando gente. (ibid.)

\footnotetext{
${ }^{6}$ Entrevista de Emilio Crenzel a Pablo *, Buenos Aires, 10 de noviembre de 2009. En los casos que los nombres de los entrevistados están modificados y sus apellidos omitidos se debe a un pedido expreso de los entrevistados.
} 
En este sentido, al recordar el clima que predominaba en el barrio en 1976, Pablo señala que "todo el mundo estaba paralizado, yo pensé que me podían venir a buscar pero no me quise ir. Pensaba me van a llevar, me van a meter preso, sabíamos que la cosa venía mal, desde antes del golpe”. Su grupo político esperaba, dice, una represión similar o incluso más virulenta, pero dentro de similares marcos a la que había desenvuelto diez años atrás durante la dictadura de la autodenominada Revolución Argentina (1966-1973) (ibid.).

La realidad, sin embargo, fue muy diferente a la represión rememorada y esperada. Por testimonios de vecinos y de compañeros de militancia, Pablo supo de la participación de los integrantes del grupo "SWAT", entre ellos el comisario Nicastro, jefe del grupo en secuestros y detenciones. Esto fue un indicio inequívoco, para él, de la vinculación entre quienes ejercieron la represión en el hospital y en el barrio. Sin embargo, nunca imaginó que en el propio hospital estuviera localizado un Centro Clandestino (ibid.).

Esta invisibilidad del centro clandestino se reproducía, incluso, al interior del propio predio del hospital, pese a que al ingresar al nosocomio había soldados apostados, que por los pasillos del hospital circulaba gente armada del referido grupo "SWAT" quienes actuaban a la vista de médicos, técnicos, enfermeras y de los pacientes que concurrían al establecimiento. Una psiquiatra que atendía pacientes en forma privada en los barrios aledaños al hospital e integraba el servicio de clínica médica que funcionaba en el Chalet originariamente destinado a la morada del director del hospital y que, tras el golpe de Estado, se convirtió en centro clandestino recuerda que

[...] la ironía es que en la casa del director se hacían los grupos terapéuticos, se usaba solamente para los grupos terapéuticos de psiquiatría, no se usaba para otra cosa y ese lugar fue centro de detención. Tras el golpe, nos prohíben inmediatamente hacer terapia de grupo. Era una casa preciosa, los pacientes sentados en sillones, un montón de habitaciones. Los de psiquiatría usábamos esa casa para hacer los grupos terapéuticos. Cuando llega la intervención, se deja de hacer terapia de grupo de un día para el otro y se van los sesenta concurrentes. Y en esa casa, empiezan a construir. Decíamos, mirá como construyen paredes para separarnos de la villa Carlos Gardel y ponen unos reflectores. Entonces, no hacíamos más grupo ni entrábamos ahí. Estaban los de SWAT en la casa. Pero mirá que ironía de la vida, de hacer grupo terapéutico, eso pasó a ser centro clandestino. Y nunca se nos ocurrió pensar que en realidad esos ladrillos que pusieron y los reflectores eran porque ahí había un centro clandestino. Decíamos estos tipos tienen miedo de la villa, no se 
te ocurre que va a haber un centro clandestino ahí donde estabas trabajando hacía sólo unas semanas y que el Dr. Roitman de quien sabíamos que estaba desaparecido se encontraba allí".?

La entrevistada se integró en 1982 a un organismo de Derechos Humanos, la Asamblea Permanente por los Derechos Humanos, tras abrirse el período de transición política, luego de la derrota en la guerra por la posesión de las Islas Malvinas en junio de ese año, de la Argentina ante el Reino Unido. Sitúa alrededor de 1979, tres años después de haber dejado el hospital, el momento en que supo el carácter sistemático que estaban revistiendo las desapariciones en el país y que la condición mayoritaria de los desaparecidos era haber sido asesinados tras su cautiverio. ${ }^{8}$

En síntesis, estos entrevistados dada su participación en redes asociativas o políticas tuvieron conocimiento tempranamente de la existencia de desaparecidos y de la responsabilidad estatal en esos hechos. Sin embargo, fueron constituyendo paulatinamente conocimiento acerca de la dimensión, atributos y naturaleza del sistema clandestino de desaparición forzada. Específicamente, sólo tomaron conocimiento de la existencia del Centro Clandestino localizado en el hospital tras recuperarse la democracia política.

Entre estos entrevistados el carácter procesual de la elaboración de conocimiento sobre el sistema de desaparición estuvo determinado y afectado, en primer lugar, por una serie de rupturas de relaciones sociales: de los círculos de militancia, en un caso, de las redes profesionales por el otro.

En segundo lugar, por la pervivencia de representaciones sociales forjadas a partir de experiencias represivas previas.

Como se desprende del testimonio del militante armado, la implementación del sistema de desaparición desnudó la ruptura del "horizonte de expectativas" (Koselleck, 1993: 341-342) de la militancia política radicalizada para comprender el cariz que asumía la nueva política represiva implementada desde el Estado. Este horizonte se había constituido a partir de las anteriores experiencias de confrontación con las fuerzas de seguridad del Estado que involucraban formas de represión convencional: la cárcel política y la tortura. La pervivencia de estos marcos operó como obstáculo para imaginar la novedad y el cariz que asumía la decisión dictatorial de implementar un exterminio clandestino, como política estatal. Con características

\footnotetext{
${ }^{7}$ Entrevista de Emilio Crenzel a Elina Aguiar, Buenos Aires, 25 de noviembre de 2009. Aguiar integraba el equipo de psiquiatría del Hospital Posadas en 1976. El Dr. Roitman fue visto en cautiverio, en muy mal estado físico, por la enfermera Gladis Cuervo en el Centro Clandestino del Hospital Posadas. Para el testimonio de Cuervo, ver CONADEP, 1984: 149.

${ }^{8}$ Entrevista de Emilio Crenzel a Elina Aguiar, Buenos Aires, 25 de noviembre de 2009.
} 
diferentes, pero con igual sentido, el segundo testimonio revela que las huellas visibles del aparato represivo (los reflectores, los paredones, la presencia militar y policial en el hospital) fueron inscriptas dentro de una matriz de sentido conocida, la de la represión tradicional. Sin embargo, en ambos casos, la intensidad de la represión o el conocimiento de los lazos entre los represores que operaban en el barrio y en el hospital no bastaron para que tomaran conocimiento de la convivencia y yuxtaposición de la normalidad y del estado de excepción en el predio del hospital.

En ambos casos, la combinación entre visibilidad y ocultamiento, entre publicidad y secreto, propios del sistema de desaparición forzada, requirió de estos entrevistados un tiempo socialmente necesario mucho mayor en relación al que les demandó las anteriores experiencias represivas - donde las características de los hechos de violencia política eran conocidos y sus responsables se identificaban -, para conocer e integrar, en un marco de sentido, las fases clandestinas y públicas del sistema de desaparición.

\section{El hospital rojo}

Otros entrevistados evocan de manera diferente el pasado de violencia política y dictadura. Daniel tiene sesenta años y vive y trabaja hace cuarenta como albañil en el barrio Carlos Gardel. Fue uno de los tantos trabajadores de la construcción que participó de la edificación de los monoblocks del barrio Pujadas y luego trabajó, de manera intermitente, en tareas de mantenimiento en el hospital Posadas. A diferencia de los entrevistados anteriores, no tiene parientes o allegados desaparecidos ni afectados por la represión y tampoco participó en actividades políticas o asociativas.

Daniel recuerda que en el barrio circulaba con fuerza la idea de que el Posadas era un "Hospital Rojo". Se decía que en 1973 habían ingresado médicos jóvenes, que eran sindicalistas y de filiación comunista o montonera. Personalmente, evoca ese tiempo como un período en el cual en el hospital se hacían frecuentemente reuniones y encuentros políticos de los que participaban "los villeros" de Carlos Gardel y que escuchó, en el barrio, que varios de los que participaban de estas actividades concurrían armados. También, recuerda las actividades de los médicos y técnicos del Posadas en el barrio. Era un tiempo como ahora, me asegura, de intranquilidad. Se cometían a diario hechos delictivos - robos, asaltos a personas y a comercios - cuyos autores, dice, eran amparados en el hospital. Los "villeros", señala, parecían ser quienes decidían qué se hacía y qué no se hacía en el Posadas.

\footnotetext{
${ }_{9}$ Entrevista de Emilio Crenzel a Daniel *, Morón, 30 de marzo de 2009.
} 
Daniel recuerda nítidamente el día 28 de marzo de 1976, fecha de la ocupación militar del barrio y del hospital. Si bien evoca que tras él a los pocos días tuvo miedo cuando le pidieron sus documentos personales y lo palparon de armas en un retén del ejército, asegura que tras ello se habituó y consideró normal la presencia de los uniformados en el barrio. Era un control minucioso, un tanto molesto para la población del barrio, pero era necesario, dice, y afirma que nunca tuvo problemas con los soldados. Por el contrario, a partir de esta situación en el barrio se comenzó a vivir más tranquilamente.

Señala Daniel que también se comentaba que el hospital había servido para atender a guerrilleros heridos. Decían, me señala con seguridad, que había un quirófano clandestino en el séptimo piso del hospital donde los atendían. "Yo nunca lo vi", aclara. También destaca que escuchó que cuando los militares ocuparon el hospital hallaron un gran depósito de armas pertenecientes a la guerrilla. Daniel asegura también que se comentaba que existía un túnel que comunicaba secretamente al barrio con el hospital y a través del cual circulaban armas y personas y que en la imprenta del Posadas se imprimían volantes montoneros.

Daniel no cree que en el hospital haya funcionado un Centro Clandestino. Me asegura que eso es imposible, que los militares hicieron todo a la luz del día y que, si hubiese existido algo semejante, él no lo podría desconocer: "Vivo en el barrio desde que nací. Eso pudo haber pasado en la $\mathrm{ESMA}^{10}$, no aquí", afirma convencido. Si recuerda que hubo familias que sorpresivamente se mudaron del barrio, que asistió a operativos militares en casas vecinas, pero realizados "siempre por derecha", dentro de la legalidad. Daniel asegura que escuchó que había desaparecidos en el barrio, pero siempre creyó que eran cuentos de gente que había estado en la guerrilla y sus hijos se habían ocultado o habían muerto en enfrentamientos con la policía o el ejército. "Nunca supe de una detención injusta", dice. Ahora que pasó el tiempo, admite que pudo haber ocurrido algún caso, pero dice no estar seguro de ello. Sus recuerdos se complementan con una valoración positiva del "orden" que trajo el gobierno militar y las posibilidades

\footnotetext{
${ }^{10}$ Escuela de Mecánica de la Armada, el mayor Centro Clandestino de Detención del país, en el cual se calcula que estuvieron recluidos 5 mil desaparecidos. Adquirió un carácter emblemático debido a la gran cantidad de desaparecidos cautivos en sus instalaciones, a que allí estuvieron cautivos desaparecidos reconocidos socialmente como el escritor Rodolfo Walsh, la primera presidenta de las Madres de Plaza de mayo, Azucena Villaflor, entre otros y a los sobrevivientes de las desapariciones que, tras ser liberados por sus captores, testimoniaron públicamente sobre las características que revistió su cautiverio. Desde 2004, la ESMA se ha constituido en un Espacio para la Memoria de los crímenes del terrorismo de Estado.
} 
de ascenso social que tuvo en esos años: "Edifiqué mi casita, y pude mandar a mis hijos al colegio y eso, en este país, no es poco".

Las evocaciones de Daniel combinan las experiencias directas que tuvo personalmente en los tiempos de dictadura en el barrio con la referencia a comentarios, rumores y relatos producidos por otros, sin especificar quién fue el portador y transmisor de la interpretación sobre los sucesos a los que refiere. En todos los casos, estos rumores reproducen los argumentos castrenses y de la prensa escrita favorable a la dictadura los cuales acompañaron la ocupación militar del hospital y del barrio. Su mirada del pasado de violencia política describe un escenario signado por el desarrollo de una confrontación militar, una guerra. Por ello, las personificaciones que sobresalen en su discurso revisten las identidades de guerrilleros y militares y las violencias de Estado son inscriptas y justificadas en función de ese contexto.

Sin embargo, en ciertos pasajes de su testimonio, las características difusas del rumor y el comentario sin sujeto eclipsan no sólo la identidad del transmisor, la cual queda en el anonimato, sino que localizan al receptor a cierta a distancia, como si escuchara una narración que hace suya pero que es en principio ajena, a partir de lo cual queda librado de responsabilidad frente a la gravedad de los hechos de los que toma conocimiento. Además, el contenido de la veracidad de lo transmitido queda entre paréntesis, en suspenso, lejos de la certeza que caracteriza a los relatos legitimados. Pese a esta ambigüedad, Daniel hace suyo el mensaje y se convierte en su emisor, contribuyendo a su reproducción.

La negación en el discurso de Daniel acerca de la existencia del centro clandestino en el hospital o sus dudas sobre la existencia de desaparecidos no excluyen, sin embargo, el reconocimiento de la existencia de un clima de férreo control social en la zona o incluso de desaparecidos recluidos en el Centro Clandestino emblemático de la dictadura, la Escuela de Mecánica de la Armada, pero estos acontecimientos son evocados e interpretados de manera favorable por el entrevistado o relegados, en el caso de la mención a la ESMA, como parte de una realidad ajena a la que se vivía en el Hospital y en el barrio.

Sus dichos se enmarcan en recuerdos atravesados por el temor respecto al período de radicalización y violencia política anterior al golpe, tiempo percibido, además, por la generalización de la violencia social y asimilado a las circunstancias del presente y por la valoración positiva del "orden" impuesto por la dictadura. En ese sentido, su testimonio se inscribe en los señalamientos de Lechner (1992), quien destacó que las promesas autoritarias de orden convocan no sólo al miedo de algunos, sino que responden además a los deseos y miedos de otros. 
Su relato acerca de la represión estatal no esgrime una negación total, llana, de lo sucedido, sino una de carácter interpretativo, la cual comporta la admisión de ciertas condiciones y hechos, en especial aquellos propios de las facetas públicas de la represión, pero encuadrados en un marco de comprensión dentro del cual estos son asimilados, normalizados y/o valorados positivamente. Un indicador de ello es la inscripción por parte de Daniel de su experiencia personal ante el retén militar la cual, según él, rápidamente la incorporó, sin más sobresaltos, como una experiencia más de la vida cotidiana.

\section{Memorias destello}

Las evocaciones de la represión por parte de Daniel, al margen de la matriz interpretativa en la que se inscriben, dan cuenta de la presencia cotidiana de la violencia de Estado en el barrio circundante al hospital. La capilaridad diaria del control y de la represión se reproduce en otros testimonios, los cuales se enmarcan, sin embargo, en otra orientación de sentido. Estos recuerdos emergen ya no en un relato articulado como en los casos anteriores, sino de forma más inorgánica, como destellos que alumbran escenas y momentos particulares de la violencia política, los cuales adquieren en su mayoría inteligibilidad para los entrevistados, ex post facto. En ninguno de estos testimonios emerge la existencia de una interpretación comprensiva del sistema de desaparición contemporánea a su ejercicio que supusiera la integración de las fases públicas y visibles de este crimen con sus fases ocultas en un relato con sentido del proceso que se estaba desenvolviendo en el Hospital, en el barrio y mucho menos que el mismo revistiese un alcance nacional y sistemático.

Esther tiene 45 años, tiene un pequeño comercio de ropa, y nació y se crió en la localidad de Morón, cerca del Hospital Posadas. Desde hace cuarenta vive en el barrio Carlos Gardel. Dice no recordar que allí existiera un barrio llamado Mariano Pujadas. Esther era adolescente cuando el hospital y el barrio fueron ocupados por el ejército. Desde fines de 1975, concurría periódicamente al hospital ya que tenía un problema cardiológico. Recuerda que tras la ocupación militar del hospital, estaba siendo atendida cuando varios soldados irrumpieron en el consultorio y le solicitaron a ella y a la profesional que la atendía identificarse. Luego las requisaron a ambas y revisaron también los cajones, la camilla y los armarios del consultorio. Evoca que, en ese instante, alcanzó a divisar desde la ventana de la sala un tanque de guerra en la playa de estacionamiento del hospital y militares apostados en el parque. ${ }^{11}$

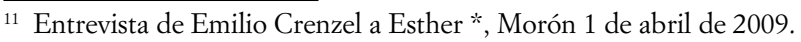


Salir del hospital ese día, recuerda, fue una odisea. En cada piso había retenes militares y quienes pasaban por allí debían identificarse y sus nombres eran chequeados por los soldados en unas listas. Esther me comenta que también vio a grupos de empleados y médicos conducidos con las manos en alto, caminando por los pasillos custodiados por los soldados. A cada momento, los militares decían que estaban buscando guerrilleros. Sin embargo, ella descree de ese argumento y afirma que las detenciones afectaron en todos los casos a "gente inocente". ${ }^{12}$

Esther siguió concurriendo al hospital las semanas posteriores en virtud de su tratamiento. Durante cerca de un mes, dice, se mantuvo la presencia militar en el hospital, las rondas y las requisas. Supo que varios médicos y enfermeras habían sido detenidos, que fueron concentrados en el salón de actos del hospital y luego, encapuchados, conducidos en camiones militares. Se ignoraba su destino. Había rumores de que eran trasladados, en calidad de presos, al sur del país. El terror que le provocaba la presencia militar en el barrio y el hospital la condujo a compartir sólo con su marido esas experiencias, y no volvió a ir al hospital tras el fin de su tratamiento.

Cristina vivía en el barrio Pujadas y trabajaba como auxiliar de enfermería en el Posadas. Relató que durante la primera semana de la intervención, pudo ver desde una ventana del cuarto piso, que un camión celular había estacionado en la puerta del Hospital, y que metían dentro de éste a las personas que habían sido detenidas, conforme a unas listas que tenían en su poder las fuerzas represivas. Los militares, al darse cuenta de que ella y otras personas miraban la escena, efectuaron varios disparos sobre las ventanas y dieron la orden, a través de un megáfono, de que las cerraran. ${ }^{13}$

Luisa, empleada doméstica y moradora del mismo barrio, pudo ver desde las ventanas del hospital cómo un grupo de detenidos eran llevados "con la parte del saco por encima de sus cabezas" y "subidos a camiones celulares" y que había escuchado que habían sido detenidas aproximadamente unas treinta personas. ${ }^{14}$ Es decir, el proceso relacionado con la individualización, detención y traslado de las víctimas para ser interrogados es evocado mediante imágenes vividas por estos entrevistados.

Por el contrario, la existencia y localización del centro clandestino en el predio del hospital, era mayoritariamente desconocida. Alfredo tiene sesenta y dos años, es plomero y vivía en 1976 en las inmediaciones del hospital.

\footnotetext{
${ }^{12}$ La condición de inocencia de las víctimas de la represión estatal ha sido uno de los pilares discursivos del movimiento de derechos humanos. Sobre la conformación del movimiento de derechos humanos en Argentina y sus matrices discursivas, véase Jelin, 1995.

13 Entrevista de Emilio Crenzel a Cristina *, Morón 10 de abril de 2009.

${ }^{14}$ Entrevista de Emilio Crenzel a Luisa *, Morón 29 de abril de 2009.
} 
Recuerda que, durante las noches, escuchaba disparos con armas que venían de la zona del parque, donde estaba la casa del director del hospital y la del administrador. Estos disparos lo conmocionaron. Sumamente preocupado, se dirigió con su mujer a la dirección del hospital para preguntar sobre este hecho. El director les dijo la primera vez que no había pasado absolutamente nada. La segunda, que no se preocuparan, que se trataba de personas de la villa que intentaban ingresar al hospital para robar. Ellos, en principio, le creyeron, aunque les parecía muy sospechoso que el lugar de donde provenían los disparos estuviese cercado, con personal militar apostado y con reflectores que iluminaban toda la zona. ${ }^{15}$

También, recuerda que otro vecino le dijo que los militares lo tranquilizaron afirmándole que se trataba de prácticas de tiro, pero eso no le conformó ya que la mayoría de las veces los disparos se escuchaban de madrugada. Señala, finalmente, que sólo supo del funcionamiento del centro clandestino en el hospital tras el retorno de la democracia, la investigación de la CONADEP en el Hospital Posadas y la publicación del informe Nunca Más.

Marta vivía en el barrio Carlos Gardel y era enfermera en tiempos de la ocupación militar. Recuerda que la zona del "Chalet" era un área restringida para el personal, pero para ella era un secreto a voces que en aquel lugar permanecían personas detenidas. Recordó que un día mientras dormía en una guardia "fue despertada por tiros que se escuchaban cerca" y que luego, al día siguiente preguntó que sucedía a uno de los integrantes del grupo "SWAT", cuyo nombre no recuerda, y que éste le contestó que habían repelido un ataque villero. Luego, en otra oportunidad alcanzó a ver cómo una mujer encapuchada era introducida en "El Chalet". Sin embargo, pensaba que esas personas eran interrogadas, seguramente maltratadas pero no asesinadas y que los responsables de ello eran exclusivamente el grupo "SWAT", al que no identificaba plenamente como parte de las fuerzas represivas del Estado. ${ }^{16}$

Estos testimonios ponen en cuestión que existiera una actitud fruto de una elección deliberada o, eventualmente como resultado de un mecanismo de negación inconsciente de carácter colectivo. En ciertos casos, se verifica que la ruptura de las relaciones sociales como efecto del terror y de la intensidad de la represión operó como frontera para la elaboración de conocimiento integral sobre las características de la represión. Ello se tradujo en el repliegue hacia una interioridad compartida con pocos, la pareja, algún vecino, es decir en el ejercicio de una "memoria privada" de lo sucedido

\footnotetext{
${ }_{15}$ Entrevista de Emilio Crenzel a Alfredo *, Morón 25 de febrero de 2009.

${ }^{16}$ Entrevista de Emilio Crenzel a Marta *, Morón 25 de febrero de 2009
} 
simultánea al quiebre o suspensión de relaciones sociales del pasado. ${ }^{17}$ En otros casos, las señales evidentes de la represión, incluso las provenientes de experiencias directas y sensoriales, algunas veces mediadas por celosías, ese símbolo depositario del secreto (Giraud, 2006) utilizadas tanto para ver como para esconder la mirada ante otro, no bastaron para que estos entrevistados vislumbraran las fases ocultas de las violencias de Estado.

Ello se debió, por un lado, a la propia naturaleza del sistema de desaparición. Como señala García Castro (2002) para el caso chileno, el conocimiento del sistema clandestino se esparció mediante un juego de visibilidad y ocultamiento que diseminaba a la vez información y secreto pero dificultaba la constitución de su conocimiento integrado como sistema. Por otro, a la carencia de marcos dialógicos compartidos, o a su carácter limitado, fruto del terror imperante que impidió que estos entrevistados inscribieran los indicios provenientes de sus registros sensoriales y fruto de "experiencias directas" con la represión de Estado e indirectas, producto de los rumores que circulaban en su barrio, en un relato con sentido. Ello, les hubiese posibilitado arribar a otras conclusiones sobre los atributos y la naturaleza de la represión estatal. Por último, la interacción con los perpetradores del sistema de desaparición, cuando estos entrevistados los interpelaron, parece haber movilizado entre ellos un sistema perverso. Se trataba de un régimen permanentemente renovado, signado por una díada constituida por la necesidad de la creencia y la confianza en la voz oficial y la incredulidad que ella suscitaba al ser interrogada y desmentida por la contrastación, mediante las propias experiencias, con las manifestaciones de la represión.

\section{Conclusiones}

Los testimonios analizados en estas páginas dan cuenta de ciertas evocaciones de los vecinos del barrio adyacente al hospital Posadas acerca de sus experiencias durante la represión dictatorial en la zona. Forman parte de una primera aproximación exploratoria de una investigación más amplia sobre este tema. Por ello, las conclusiones que aquí se presentan son provisorias. En este sentido, no han sido objeto hasta el momento la comparación entre las memorias sobre estos hechos en ambos barrios adyacentes al hospital, las dimensiones de género, clase y etarias que puedan dar cuenta, en términos explicativos, de las diferencias en el contenido de los recuerdos de los entrevistados.

\footnotetext{
${ }^{17}$ Nun (1984: 162) utiliza el concepto de memoria privada para retratar la inscripción o elaboración en términos individuales y no como fruto de un proceso social, de determinadas experiencias sociales y políticas.
} 
Sin embargo, interesa destacar que el conjunto de los entrevistados guarda recuerdos acerca de experiencias directas con la represión política. También, que sus evocaciones revelan un aspecto en común, la referencia a la ruptura de relaciones sociales, o a la limitación que éstas sufrieron producto del terror y de la intensidad de la represión. Fueron los contextos dialógicos, los cuales como afirmó de manera pionera Halbwachs (2004 [1925]) permiten la elaboración de experiencias sociales, los que dificultaron - por su carácter privado y restringido - el conocimiento y/o la integración de las facetas públicas y clandestinas de la represión política dentro del conjunto de prácticas represivas que desenvolvía la dictadura. Es decir, fueron esos contextos limitados de enunciación e interrogación de la realidad los que enmarcaron socialmente la producción de conocimiento sobre el sistema de desaparición forzada.

Cabe resaltar, también, como rasgo común de estos testimonios, más allá del grado de afectación por la represión de Estado de sus emisores o las claves narrativas y explicativas en las que se enmarcan sus evocaciones, el desconocimiento mayoritario que manifestaron sobre las prácticas que comportaba la faz clandestina del sistema de desaparición, mientras estaba en curso en el hospital y en la zona. Como otro atributo común, cuando emerge un saber sobre ciertas prácticas represivas que formaban parte de ese sistema, éste posee un carácter sumamente fragmentado, parcial y rudimentario que no logra dar cuenta de la naturaleza, los atributos y responsables del sistema de desaparición. El hecho de que este desconocimiento atraviese tanto a entrevistados que sufrieron la represión, a aquellos que la justifican y a quienes se presentan exclusivamente como testigos parciales de algún suceso represivo, desplaza toda posible asociación entre la manifestación de ignorancia con un posible ejercicio de la negación o una forma de obliterar responsabilidades.

Aún quien era parte de una estructura militante no vislumbraba el cariz que asumiría la represión, o la localización en el hospital de un centro clandestino. Finalmente, los entrevistados que no formaban parte de las experiencias militantes y tampoco justifican la represión, fueron testigos de hechos represivos, en su mayoría de carácter público, aislados o concatenados, que no pudieron integrar en un relato con sentido. En estos casos, los testimonios evidencian que las fases clandestinas del crimen quedaban encubiertas no sólo por la negación o las explicaciones oficiales sobre esas prácticas, sino también por el terror, la ausencia de marcos dialógicos compartidos y el despliegue ostensible de la fuerza de parte de sus personificaciones estatales.

En este trabajo se procuró poner en discusión dos imágenes igualmente totalizadoras acerca del conocimiento que circulaba en la sociedad argentina 
respecto a las desapariciones. La primera, la proposición que fundó el informe Nunca Más que postuló la ignorancia de la sociedad respecto del terror de Estado y la segunda, surgida en los años noventa del siglo pasado, que propuso el conocimiento pleno de parte de la sociedad de los crímenes dictatoriales. Estas imágenes ocluyen la novedosa naturaleza represiva que supuso el sistema de desaparición, los desafíos que planteó para su conocimiento y reconocimiento, al combinar fases públicas con clandestinas y las díadas de credulidad e incredulidad que le eran inherentes y que potenciaban los perpetradores mediante sus discursos y explicaciones sobre la represión. Las explicaciones mencionadas impiden dar cuenta de la fragmentación y la heterogeneidad del conocimiento socialmente disponible sobre este sistema y sus propiedades mientras funcionaba. Este estudio exploratorio procuró poner de manifiesto la existencia de una trama social más compleja que signó la elaboración de conocimiento, la circulación de ideas y de representaciones sobre el sistema de desaparición que las que proponen las imágenes totalizadoras, a partir del examen de un caso específico pero particularmente propicio dada la convivencia de la normalidad y la excepción en el Hospital Posadas.

\section{Referencias bibliográficas}

Álvarez, Mariano (2003), Esperanzas caminando. El Posadas: una experiencia de movilización y participación social en la argentina de los 70'. Trabajo final del Seminario de Investigación Histórica, I.E.S, número 1, Alicia Moreau de Justo. Buenos Aires, mimeo.

Arquidiocese de São Paulo (1985), Brasil: Nunca Mais. Petrópolis: Editora Vozes.

Auto de procesamiento (2007), Causa Hospital Posadas. Buenos Aires.

Batallón de Inteligencia 601 (1976), "Proceso en el Policlínico Posadas desde el año 1972 hasta la fecha”. Archivo DIPBA, legajo 6092, Mesa "D(S)", Carpeta Varios, Comisión Provincial por la Memoria de la provincia de Buenos Aires.

Bonanotte, César et al. (s/f), "Transición democrática y formas de poder popular". Trabajo final del Seminario de Investigación a cargo de Ernesto Villanueva, Carrera de Sociología, Universidad de Buenos Aires, mimeo.

Browning, Christopher (1992), Ordinary Men. Reserve Police Battalion 101 and the Final Solution in Poland. New York: Harper-Collins.

Calveiro, Pilar (1995), Poder y desaparición: campos de concentración en Argentina, 1976-1980. México: Tesis de Maestría en Ciencia Política, Universidad Nacional Autónoma de México.

Cohen, Stanley (2001), States of Denial. Knowing about Atrocities and Suffering. Cambridge: Cambridge UP. 
Comisión Nacional de Verdad y Reconciliación (1991), Informe de la Comisión Nacional de Verdad y Reconciliación. Santiago de Chile: LOM.

Comisión Nacional sobre la Desaparición de Personas (CONADEP) (1984), Nunca Más. Informe de la Comisión Nacional sobre la Desaparición de Personas. Buenos Aires: EUDEBA.

Crenzel, Emilio (2008), La historia política del Nunca Más. La memoria de las desapariciones en la Argentina. Buenos Aires: Siglo XXI.

García Castro, Antonia (2002), La mort lente des disparus au Chili sous la négociation civils-militaires (1973-2002). París: Maisonneuve \& Larose.

Giraud, Claude (2006), Acerca del secreto. Contribución a una sociología de la autoridad y el compromiso. Buenos Aires: Biblos.

Halbwachs, Maurice (2004), Los marcos sociales de la memoria. Barcelona: Anthropos [11925].

Jelin, Elizabeth (1995), "La política de la memoria: el movimiento de Derechos Humanos y la construcción de la democracia en Argentina”, en Carlos Acuña et al., Juicio, castigos y memorias. Derechos Humanos y justicia en la política Argentina. Buenos Aires: Nueva Visión, 101-146.

Johnson, Eric; Heiz-Reuband, Karl (2006), What Ke Knew. Terror, Mass Murder and Everyday Life in Nazi Germany. New York: Basic Books.

Koselleck, Reinhardt (1993), Futuro pasado: para una semántica de los tiempos históricos. Barcelona: Paidós.

Laqueur, Walter (1980), The Terrible Secret: An Investigation into the Suppression of Information about Hitler's "Final Solution". Londres: Weidenfeld and Nicolson.

Lechner, Norbert (1992), "Some People Die of Fear. Fear as a Political Problem", en Juan Corradi et al. (coords.), Fear at the Edge. State Terror and Resistance in Latin America. Berkeley y Los Ángeles: California University Press, 25-38.

Malamud Goti, Jaime (2000), Terror y justicia en la Argentina. Buenos Aires: Ediciones de la Flor.

Mannheim, Karl (1993), Ideología y utopía. Introducción a la sociología del conocimiento. México: Fondo de Cultura Económica.

Novaro, Marcos; Palermo, Vicente (2002), La dictadura militar 1976/1983. Del golpe de Estado a la restauración democrática. Buenos Aires: Paidós.

Nun, José (1984), “Averiguación sobre algunos significados del Peronismo”, en Oscar Oszlak (coord.), Proceso, crisis y transición. Buenos Aires: CEAL, 145-183.

Piaget, Jean (1985), La toma de conciencia. Madrid: Morata.

Pollak, Michael (1990), L'expérience concentrationnaire. Essai sur le maintien de l'identité sociale. París: Métaillé.

Portelli, Alessandro (1991), "Lo que hace diferente a la historia oral”, en Dora Schwarzstein (coord.), La historia oral. Buenos Aires: CEAL, 36-52. 
SERPAJ Uruguay (Servicio Paz y Justicia para América Latina) (1989), Nunca Más. Montevideo: SERPAJ.

Theidon, Kimberly (2004), Entre prójimos. El conflicto armado interno y la política de la reconciliación en el Perú. Lima: Instituto de Estudios Peruanos.

Vezzetti, Hugo (2002), Pasado y presente. Guerra, dictadura y sociedad en la Argentina. Buenos Aires: Siglo XXI. 